Revista Brasileira de Agricultura Irrigada v.12, nº.5, p. 2932 - 2943, 2018

ISSN 1982-7679 (On-line)

Fortaleza, CE, INOVAGRI - http://www.inovagri.org.br

DOI: $10.7127 /$ rbai.v12n500887

Protocolo 887.18 - 27/02/2018 Aprovado em 04/09/2018

\title{
POTENCIAL CLIMÁTICO PARA CULTIVO DA VIDEIRA NO ALTO SERTÃO SERGIPANO
}

\author{
Juracy Barroso Neto ${ }^{1}$, Inaja Francisco de Sousa ${ }^{2}$
}

\begin{abstract}
RESUMO
A caracterização climática realizada em menor escala é um passo importante para aperfeiçoar a produção em uma determinada região, tornando-se possível identificar os mesoclimas mais favoráveis ao cultivo. Assim como o Submédio do São Francisco, a região do Alto Sertão Sergipano está localizada no Semiárido brasileiro, o qual apresenta crescente potencial para o cultivo da videira. O estudo buscou avaliar a aptidão e o potencial da viticultura da parcela semiárida sergipana, caracterizando o tipo de produção, os riscos climáticos e identificando as melhores épocas de cultivo, variedades adaptáveis, através dos índices climáticos do Sistema de Classificação Multicritério Geovitícola, que combinam fatores hídricos, heliotérmicos e nictotérmicos. A região apresentou condições favoráveis para viticultura, tanto para produção de uvas de mesa, quanto para uvas finas destinadas a vitivinicultura. As melhores épocas para a produção são as que sincronizam o período de colheita com os meses mais secos (agosto a novembro), bem como foi possível observar um maior acúmulo térmico para os ciclos de 04 meses nos períodos Primavera-Verão e Verão-Outono.
\end{abstract}

Palavras-chave: viticultura, caracterização climática, zoneamento, Vitis sp.

\section{CLIMATE POTENTIAL FOR CULTIVATION OF VINE IN ALTO SERTÃO SERGIPANO}

\begin{abstract}
The small-scale climatic characterization is an important step to improve production in a given region, making it possible to identify mesoclimates more favorable to the crop. Like the Submédio do São Francisco, the Alto Sertão Sergipano region is located in the Brazilian semiarid, which has an increasing potential for grapevine cultivation. The aim of this study was to evaluate the suitability and potential of viticulture in the semiarid region of Sergipe, characterizing the type of production, climatic risks and identifying the best growing seasons, adaptable varieties, through the climatic indexes of the Multicriteria Geovitícola Classification
\end{abstract}

${ }^{1}$ Graduando em Engenharia Agronômica, Universidade Federal de Sergipe - UFS, barroso.neto@hotmail.com; ${ }^{2}$ Prof. Doutor, Departamento de Engenharia Agronômica da Universidade Federal de Sergipe - UFS, inajafrancisco@gmail.com. 
System, which combine hydric, heliothermic, and nictothermal factors. The region presented favorable conditions for viticulture, both for the production of table grapes and for fine grapes destined to wine-growing. The best seasons for production are those that synchronize the harvest period with the driest months (august to november), as well as a higher thermal accumulation for the four-month cycles in the Spring-Summer and Summer-Autumn periods.

Keywords: viticulture, climatic characterization, zoning, Vitis sp.

\section{INTRODUÇÃO}

A produção de uvas por todo o Brasil, principalmente no Nordeste do país, demonstra a grande capacidade de adaptação da videira às mais diferentes condições de clima. Conhecer essas condições climáticas da região e do local de cultivo é fundamental para tomada de decisão sobre qual será o tipo de produção, ampliar as possibilidades do mercado local e definir melhores épocas de cultivo.

Em condições tropicais, a viticultura apresenta uma série de particularidades de manejo, em virtude da adaptação e comportamento fisiológico diferenciado das condições subtropicais e temperadas (LEÃO; MAIA, 1998). As plantas vegetam continuamente e não apresentam fase de dormência, o que possibilita realizar ciclos sucessivos de produção, em qualquer época, com até duas colheitas por ano (CAMARGO; OLIVEIRA, 2001).

No nordeste brasileiro, a produção de uvas irrigadas no Vale do Submédio São Francisco, localizado entre os Estados da Bahia e Pernambuco, tem destacado a região como grande produtora, superando as limitações hídricas do semiárido e enriquecendo o mercado com bons produtos. Já o Estado do Sergipe não possui tradição no cultivo da videira, bem como não há registros de produção segundo os últimos dados de produção agrícola (IBGE, 2016).

Recentemente, duas unidades experimentais de uva foram introduzidas no perímetro irrigado Califórnia, em Canindé de São Francisco, utilizando variedades de uvas de mesa adaptadas ao clima nordestino (cultivares já testadas com eficiência comprovada nos campos de pesquisa da Embrapa em Petrolina$\mathrm{PE})$. Apesar disso, não se tem estudado o clima geovitícola da região, de acordo com os modelos de classificação, para encontrar mais rapidamente a aptidão, ou as aptidões, dessa possível zona produtora sem depender apenas do empirismo dos produtores, o velho método de tentativa e erro.

Este trabalho teve por objetivo avaliar o potencial e a viabilidade climática para cultivo da videia na região do alto sertão sergipano, e subsidiar as decisões do produtor interessado em investir nessa atividade, identificando as melhores épocas entre poda e colheita e caracterizando a região quanto ao tipo de produção.

\section{METODOLOGIA}

\section{Caracterização da área de estudo e obtenção dos dados climáticos}

O alto sertão sergipano está inserido no semiárido brasileiro e segundo a classificação climática de Koppen, tem o clima classificado como BSsh' - muito quente, semiárido, tipo estepe, com estação chuvosa concentrada no outono e inverno.

Normais climatológicas fornecidas pelo Centro de Meteorologia da Secretaria de Estado do Meio Ambiente e Recursos Hídricos (SEMARH/SRH) para o município de Canindé de São Francisco, SE, (9 $\left.9^{\circ} 38^{\prime} \mathrm{S}, 37^{\circ} 47^{\prime} \mathrm{W}, 68 \mathrm{~m}\right)$ e Poço Redondo, SE, ( $9^{\circ} 48^{\prime} \mathrm{S}, 37^{\circ} 41^{\prime} \mathrm{W}, 167$ m) foram utilizadas para aplicação no Sistema de Classificação Climática Multicritério - CCM. Os dados consultados reúnem a média de 30 anos (1961 a 1990), e revelam números mensais de temperatura máxima, média e mínima, e precipitação.

Os cálculos foram realizados considerando o ciclo de seis meses para cultivo da videira na região, contemplando 12 ciclos (agosto a janeiro, setembro a fevereiro, outubro a março, novembro a abril, dezembro a maio, 
janeiro a junho, fevereiro a julho, março a agosto, abril a setembro, maio a outubro, junho a novembro, e julho a dezembro). Além disso, foram avaliados 04 ciclos de quatro meses, denominados de "Primavera-Verão" (outubro a janeiro), "Verão-Outono" (janeiro a abril), "Outono-Inverno" (abril a julho), e "InvernoPrimavera” (julho a outubro), considerando o dia 15 de cada mês como período inicial e final de cada ciclo.

\section{Sistema CCM}

O sistema de Classificação Climática Multicritério, desenvolvido por Tonietto e Carbonneau (2004), utiliza três índices climáticos vitícolas: índice heliotérmico (IH), índice de seca (IS) e índice de frio noturno (IF).
O IH foi desenvolvido por Huglin (1978) e procura estimar o potencial heliotérmico de uma condição climática específica, o qual está relacionado às exigências térmicas das variedades, bem como ao conteúdo potencial de açúcar das uvas. O cálculo que compreende ao somatório de todo o ciclo de produção inclui um fator de correção (K) para o comprimento do dia, para os casos em que as latitudes são mais elevadas:

Em que,

$\mathrm{IH}$ = índice heliotérmico;

$\mathrm{T}=$ temperatura média do ar $\left({ }^{\circ} \mathrm{C}\right)$;

$\mathrm{Tx}=$ temperatura máxima do $\operatorname{ar}\left({ }^{\circ} \mathrm{C}\right)$;

$\mathrm{K}=$ coeficiente do comprimento do dia, sendo neste caso atribuído o valor 1 , recomendado para regiões com latitudes $<40^{\circ}$ (TONIETTO e CARBONNEAU, 2004).

$$
I H=\sum_{\text {ínicio do ciclo }}^{\text {fim do ciclo }} \frac{[(T-10)-(T x-10)]}{2} \cdot K
$$

Adaptado por Tonietto (1999) e Tonietto e Carbonneau (2004) a partir do balanço hídrico potencial do solo de Riou (1994), o IS caracteriza o fator hídrico de uma região, informando a disponibilidade de água potencial do solo, levando em consideração a demanda climática do próprio vinhedo, a evaporação em solo sem cobertura, e a precipitação pluviométrica. Este índice também foi calculado com base no ciclo de produção e tem grande relação com as características qualitativas da uva e do vinho.

$$
I S=\mathrm{Wo}+\mathrm{P}-\mathrm{Tv}-\mathrm{Es}
$$

Onde,

IS = índice de seca;

Wo = reserva hídrica inicial útil do solo $(\mathrm{mm})$;

$\mathrm{P}=$ precipitação pluviométrica $(\mathrm{mm})$;

$\mathrm{Tv}=$ transpiração potencial do vinhedo $(\mathrm{mm})$; Es = evaporação direta a partir do solo $(\mathrm{mm})$.

$\mathrm{O}$ índice foi calculado mês a mês, com base em valores mensais de P, ETP, Tv e Es. Sendo assim, o IS é o próprio valor de W obtido no momento final seguindo as regras acima e adotando Wo $=200 \mathrm{~mm}$. A transpiração potencial do vinhedo foi calculada através da seguinte fórmula:

$$
T v=E T P . k
$$

Onde,

$\mathrm{Tv}=$ transpiração potencial do vinhedo $(\mathrm{mm})$; ETP = evapotranspiração potencial (total mensal), utilizando o método de PenmanMonteith, parametrizado pela FAO (ALLEN et al., 1998);

$\mathrm{k}=$ coeficiente de absorção da radiação pela planta de videira (que é em relação à transpiração e depende da arquitetura videira).

Os valores de $\mathrm{k}$ considerados foram 0,1 para o primeiro mês do ciclo, 0,3 para o segundo mês do ciclo e 0,5 para os demais meses (TONIETTO e CARBONNEAU, 2004).

Já a evaporação direta a partir do solo sem vegetação se deu pela expressão:

$$
E s=\frac{E T P}{N} \cdot(1-k) . J P m
$$

Onde,

Es = evaporação direta a partir do solo (mm);

$\mathrm{N}$ = número de dias do mês; 
$\mathrm{JPm}$ = número de dias de evaporação eficaz a partir do solo por mês, estimado pela equação:

Em que,

$$
J P m=\frac{P}{5}
$$

$\mathrm{JPm}=$ número de dias de vaporação eficaz a partir do solo por mês;

$\mathrm{P}=$ Precipitação (mm).

Já a condição nictotérmica associada ao período de maturação das uvas foi estimada pelo IF (TONIETTO, 1999; TONIETTO \& CARBONNEAU, 2004), que serve como indicador das características potenciais das regiões em relação aos metabólitos secundários (polifenóis, aromas, cor) nas uvas e vinhos.

$$
I F=T n
$$

Onde,

IF = índice de frio noturno;

Tn = temperatura mínima do ar do último mês do ciclo (média das mínimas do mês).

\section{Classificações dos índices do sistema CCM}

Os índices vitícolas foram classificados de acordo com os intervalos descritos na Tabela 1. Para a avaliação dos ciclos de 04 meses, os resultados foram adaptados, extrapolando os dados linearmente de acordo com o valor médio mensal.

Tabela 1. Classes do Clima Geovitícola para ciclo de seis meses (TONIETTO; CARBONNEAU, 2004).

\begin{tabular}{cccc}
\hline Índices climáticos vitícolas & Classes do clima & Sigla & Intervalo de classe \\
\hline & Úmido & IS-2 & $150<$ IS \\
Índice de Seca & Subúmido & IS-1 & $50<\mathrm{IS} \leq 150$ \\
(IS, mm) & De seca moderada & IS +1 & $-100<\mathrm{IS} \leq 50$ \\
& De seca forte & IS+2 & IS $\leq-100$ \\
\hline & Muito frio & $\mathrm{IH}-3$ & $\mathrm{IH} \leq 1500$ \\
Índice Heliotérmico & Frio & $\mathrm{IH}-2$ & $1500<\mathrm{IH} \leq 1800$ \\
$(\mathrm{IH})$ & Temperado & $\mathrm{IH}-1$ & $1800<\mathrm{IH} \leq 2100$ \\
& Temperado quente & $\mathrm{IH}+1$ & $2100<\mathrm{IH} \leq 2400$ \\
& Quente & $\mathrm{IH}+2$ & $2400<\mathrm{IH} \leq 3000$ \\
& Muito quente & $\mathrm{IH}+3$ & $3000<\mathrm{IH}$ \\
\hline Índice de Frio Noturno & De noites quentes & $\mathrm{IF}-2$ & $18<\mathrm{IF}$ \\
$\left(\mathrm{IF},{ }^{\circ} \mathrm{C}\right)$ & De noites temperadas & $\mathrm{IF}-1$ & $14<\mathrm{IF} \leq 18$ \\
& De noites frias & $\mathrm{IF}+1$ & $12<\mathrm{IF} \leq 14$ \\
& De noites muito frias & $\mathrm{IF}+2$ & $\mathrm{IF} \leq 12$ \\
\hline
\end{tabular}

\section{Necessidades térmicas e variedades}

Utilizando o conceito do índice biometeorológico com o acúmulo de temperatura em graus-dias (GD) comparou-se os valores encontrados no índice heliotérmico com as seguintes cultivares testadas em regiões do Centro-Oeste e Nordeste e suas respectivas necessidades em soma térmica (Tabela 2) [Camargo e Mandelli, (1993), Boliani (1994), Pedro Júnior et al. (1994), Boliani e Pereira (1996), Santos et al. (1998), Terra et al. (1998), Nagata et al. (2000), Murakami et al. (2002), Leão et al. (2003), Moura et al. (2007, a e b), Ribeiro et al. (2009), Ribeiro et al. (2010)]:

Tabela 2. Somas térmicas $\left({ }^{\circ} \mathrm{C}\right.$ dia) de diversas cultivares de videira (Vitis sp.), da poda à colheita.

\begin{tabular}{cc}
\hline Cultivares & $\begin{array}{c}\text { Soma Térmica }\left({ }^{\circ} \mathrm{C}\right. \\
\text { dia })\end{array}$ \\
\hline Cabernet Sauvignon & 2100 a 2200 \\
Syrah, Itália, Rubi, Brasil, Benitaka & 1900 a 2000
\end{tabular}




$\begin{array}{cc}\text { Niágara Branca e Niágara Rosada } & 1700 \text { a } 1850 \\ \text { BRS Clara, BRS Linda, BRS Morena, Perlette } & 1450 \text { a } 1600 \\ \text { Superior Seedless, Marroo Seedless } & 1300 \text { a } 1400\end{array}$

\section{RESULTADOS E DISCUSSÃO}

\section{Classificação climática geovitícola}

A região do alto sertão sergipano, representada neste estudo pelos municípios de Canindé de São Francisco e Poço Redondo, enquadra-se na definição de clima vitícola com variabilidade intra-anual, que é aquela que varia de acordo com o período de cultivo, possuindo dois grupos climáticos ao longo do ano (Tabela 3 e Tabela 4). Observaram-se as classes de Muito Quente $(\mathrm{IH}+3)$, de Noites Muito Quentes (IF-2), podendo ser de Seca Moderada (IS+1) ou Subúmido (IS-1), semelhante a região produtora do Vale do Submédio São Francisco quanto ao ciclo de seis meses, apenas diferindo que a região dos sertões pernambucano e baiano apresenta ainda mais um grupo, o de Seca Forte (IS+2).

$\mathrm{O}$ índice de Muito Quente $(\mathrm{IH}+3)$ representa a classe mais quente de clima vitícola, não havendo restrição para o amadurecimento das uvas. O privilégio de estar numa zona que tem essas características é a possibilidade de se obter mais de uma colheita por ano, como por exemplo, já acontece nas regiões de Petrolina, Vale do São Francisco, e Ludhiana, na Índia.

Tabela 3. Índice Vitícola e Grupos Climáticos de Canindé de São Francisco/SE ao longo dos 12 ciclos potenciais.

\begin{tabular}{ccccccc}
\hline & \multicolumn{3}{c}{ Índice Vitícola } & \multicolumn{2}{c}{ Classe do Clima Vitícola } \\
\cline { 2 - 6 } Período & IH & IF $\left({ }^{\circ} \mathrm{C}\right)$ & IS $(\mathrm{mm})$ & IH & IF & IS \\
\hline Agosto-Janeiro & 3497,20 & 22,2 & $-77,01$ & IH+3 & IF-2 & IS+1 \\
Setembro-Fevereiro & 3520,95 & 22,2 & $-57,51$ & IH+3 & IF-2 & IS+1 \\
Outubro-Março & 3603,85 & 22,4 & $-29,72$ & IH+3 & IF-2 & IS+1 \\
Novembro-Abril & 3562,85 & 22,0 & 14,09 & IH+3 & IF-2 & IS+1 \\
Dezembro-Maio & 3478,77 & 21,1 & 63,84 & IH+3 & IF-2 & IS-1 \\
Janeiro-Junho & 3328,47 & 20,0 & 104,14 & IH+3 & IF-2 & IS-1 \\
Fevereiro-Julho & 3219,20 & 19,5 & 125,52 & IH+3 & IF-2 & IS-1 \\
Março-Agosto & 3195,45 & 19,0 & 115,71 & IH+3 & IF-2 & IS-1 \\
Abril-Setembro & 3112,55 & 20,0 & 86,73 & IH+3 & IF-2 & IS-1 \\
Maio-Outubro & 3153,55 & 21,0 & 35,41 & IH+3 & IF-2 & IS+1 \\
Junho-Novembro & 3237,62 & 22,0 & $-21,25$ & IH+3 & IF-2 & IS+1 \\
Julho-Dezembro & 3387,92 & 22,0 & $-59,1$ & IH+3 & IF-2 & IS+1 \\
\hline
\end{tabular}


Tabela 4. Índice Vitícola e Grupos Climáticos de Poço Redondo/SE ao longo dos 12 ciclos potenciais.

\begin{tabular}{ccccccc}
\hline & \multicolumn{3}{c}{ Índice Vitícola } & \multicolumn{2}{c}{ Classe do Clima Vitícola } \\
\cline { 2 - 7 } Período & IH & IF $\left({ }^{\circ} \mathrm{C}\right)$ & IS $(\mathrm{mm})$ & IH & IF & IS \\
\hline Agosto-Janeiro & 3463,57 & 21,9 & $-71,63$ & IH+3 & IF-2 & IS+1 \\
Setembro-Fevereiro & 3502,15 & 21,9 & $-62,94$ & IH+3 & IF-2 & IS+1 \\
Outubro-Março & 3594,00 & 22,2 & $-37,21$ & IH+3 & IF-2 & IS+1 \\
Novembro-Abril & 3547,87 & 21,7 & 8,62 & IH+3 & IF-2 & IS+1 \\
Dezembro-Maio & 3462,12 & 20,7 & 59,24 & IH+3 & IF-2 & IS-1 \\
Janeiro-Junho & 3306,72 & 19,0 & 99,85 & IH+3 & IF-2 & IS-1 \\
Fevereiro-Julho & 3191,25 & 19,0 & 135,76 & IH+3 & IF-2 & IS-1 \\
Março-Agosto & 3152,67 & 18,5 & 134,13 & IH+3 & IF-2 & IS-1 \\
Abril-Setembro & 3060,82 & 19,5 & 111,39 & IH+3 & IF-2 & IS-1 \\
Maio-Outubro & 3106,95 & 20,5 & 62,29 & IH+3 & IF-2 & IS-1 \\
Junho-Novembro & 3192,70 & 21,5 & 0,67 & IH+3 & IF-2 & IS+1 \\
Julho-Dezembro & 3348,10 & 21,4 & $-43,49$ & IH+3 & IF-2 & IS+1 \\
\hline
\end{tabular}

O índice de Noites Quentes (IF-2) caracteriza a região pela maturação das uvas com altas temperaturas no período noturno, pois considera o período final do ciclo vitícola. Essa condição pode afetar negativamente a cor e o potencial aromático das uvas, já que com elevadas temperaturas as uvas concentram maiores teores de álcool, menor acidez e valores mais elevados de pH (OLLAT et al., 2002; ORDUÑA, 2010), o que pode ocasionar problemas de equilíbrio e conservação, com a presença de taninos imaturos, podendo os vinhos elaborados estarem sujeitos a degradações causadas por micro-organismos (RIBEREAU-GAYON et al., 2004 a,b).

Quanto ao índice de seca, a região pode ser incluída em duas classes, dependendo do período. A classe Sub-úmido (IS-1) do clima vitivinícola é típico da ausência de seca, porém o valor de $50 \mathrm{~mm}$ seria um valor crítico que revela a introdução de um balanço hídrico mínimo sob condições de frequentes secas, como é o caso dos valores próximos encontrados no período de dezembro a maio, portanto, um bom indicador do ponto de alteração da condição de disponibilidade de água. Algumas regiões semelhantes que caracterizaram a presença ou ausência de secas frequentes são Bordeaux, na França, e Napier, na Nova Zelândia.

A Seca Moderada (IS+1) compreende as condições em que a videira se submete a certo nível de seca. Nesta condição, a planta pode apresentar uma regulação estomática significativa, o que é geralmente favorável à maturação, como ocorre, por exemplo, nas regiões de Montpellier, França, e Funchal, em Portugal. A irrigação, portanto, é praticada em alguns casos, já que em torno de IS $<50 \mathrm{~mm}$ compreende-se ao clima do tipo mediterrâneo, com déficit de água no verão.

O maior acúmulo de temperatura em graus-dia acontece no ciclo de outubro a março tanto em Canindé de São Francisco, com IH equivalente a 3603,85, quanto em Poço Redondo, onde se obteve o valor de 3594,00. Apesar de todos os ciclos analisados apresentarem $\mathrm{IH}>3000$, no período entre abril e setembro obteve-se o menor valor de acúmulo térmico na região. O mês com a melhor possibilidade para amadurecimento das uvas, de acordo com o Índice de Frio Noturno, é agosto 
em ambos os municípios, com temperaturas mínimas de $19{ }^{\circ} \mathrm{C}$ e $18,5{ }^{\circ} \mathrm{C}$, respectivamente. E o balanço hídrico mais satisfatório se deu no ciclo de fevereiro a julho, com 125,52 mm para Canindé de São Francisco, e 135,76 mm em Poço Redondo, sendo observada em alguns períodos uma reserva hídrica do solo negativa, expressando o déficit potencial de água, tendo o menor valor encontrado no período de agosto a janeiro, com IS equivalente a -77,01 mm e $71,63 \mathrm{~mm}$, respectivamente.

Nos ciclos de quatro meses, conforme Tabela 5 e Tabela 6, através da adaptação dos dados encontrados, foi possível classificar os períodos em quatro climas vitícolas, revelando as classes de Temperado Quente $(\mathrm{IH}+1)$ e Quente (IH+2), de Noites Muito Quentes (IF-2), podendo ser de Seca Moderada (IS+1), Subúmido (IS-1) e Úmido (IS-2). O maior acúmulo em graus-dia se deu no ciclo Primavera-Verão com IH igual a 1835,55 em Canindé e 1824,15 em Poço Redondo, tendo um menor aproveitamento para os dois municípios analisados no período de OutonoInverno, com 1537,42 e 1513,62, respectivamente. Em compensação esse mesmo ciclo foi o que teve o maior resultado quando analisado o índice de seca, com 132,34 mm (Canindé de S. F.) e 138,71 mm (Poço Redondo).

Tabela 5. Índice Vitícola e Grupos Climáticos de Canindé de São Francisco/SE ao longo dos ciclos de quatro meses.

\begin{tabular}{ccccccc}
\hline & \multicolumn{3}{c}{ Índice Vitícola } & \multicolumn{2}{c}{ Classe do Clima Vitícola } \\
\cline { 2 - 7 } Período & IH & IF $\left({ }^{\circ} \mathrm{C}\right)$ & IS $(\mathrm{mm})$ & IH & IF & IS \\
\hline Primavera-Verão & 1835,55 & 22,2 & 15,82 & IH+2 & IF-2 & IS+1 \\
Verão-Outono & 1718,62 & 22,0 & 70,67 & IH+2 & IF-2 & IS-1 \\
Outono-Inverno & 1537,42 & 19,5 & 132,34 & IH+1 & IF-2 & IS-2 \\
Inverno-Primavera & 1569,97 & 21,0 & 36,52 & IH+1 & IF-2 & IS-1 \\
\hline
\end{tabular}

Tabela 6. Índice Vitícola e Grupos Climáticos de Poço Redondo/SE ao longo dos ciclos de quatro meses.

\begin{tabular}{ccccccc}
\hline & \multicolumn{3}{c}{ Clima Vitícola } & \multicolumn{3}{c}{ Classe do Clima Vitícola } \\
\cline { 2 - 7 } Período & IH & $\begin{array}{c}\text { IF } \\
\left({ }^{\circ} \mathrm{C}\right)\end{array}$ & $\begin{array}{c}\text { IS } \\
(\mathrm{mm})\end{array}$ & IH & IF & IS \\
\hline Primavera-Verão & 1824,15 & 21,9 & 6,64 & IH+2 & IF-2 & IS+2 \\
Verão-Outono & 1717,75 & 21,7 & 64,63 & IH+2 & IF-2 & IS-1 \\
Outono-Inverno & 1513,62 & 19,0 & 138,71 & IH+1 & IF-2 & IS-2 \\
Inverno-Primavera & 1544,95 & 20,5 & 44,88 & IH+1 & IF-2 & IS-1 \\
\hline
\end{tabular}

Em todos os ciclos analisados não se obteve números críticos abaixo do limite para caracterização da classe de Seca Forte, ou seja, descartando a possibilidade de efeitos frequentes de estresse, e déficit de água disponível no solo. Embora obtido este resultado, deve-se levar em conta que o valor proposto de reserva hídrica útil inicial do solo pelo sistema não se adequa às realidades dos solos da região, levando ao entendimento de que a irrigação deve ser praticada para satisfazer essa condição.

\section{Considerações climáticas e aptidão varietal}

A evapotranspiração potencial de referência (ETo) média mensal das normais 
climatológicas ao longo dos 12 meses é de 122,29 mm em Canindé de São Francisco e 123,05 mm em Poço Redondo, tendo o maior valor ocorrendo no mês de dezembro, em ambos os municípios, conforme Figura 1.

Já a precipitação média mensal é de 37 mm em Canindé e 38,83 mm em Poço Redondo, sendo o período de inverno com regime mais acentuado. Apesar da videira ser uma cultura que se adapta bem as condições adversas, ela requer não somente uma quantidade considerável de água, mas também uma distribuição de chuvas ao longo do ciclo vegetativo que possa atender as necessidades hídricas no período de brotação. Dessa forma, a irrigação se torna necessária pela pouca expressividade pluviométrica do alto sertão sergipano e pelas classificações de balanço hídrico no solo. Ainda assim, é recomendado o monitoramento nos meses mais chuvosos e controle da irrigação, para evitar o desenvolvimento de algumas doenças fúngicas da parte aérea, bem como não prejudicar fases importantes da videira, como a floração e a frutificação.

O baixo regime hídrico durante todo o ano torna-se até vantajoso para o bom desenvolvimento da videira, já que de acordo com Kischino et al. (2007) nas fases de desenvolvimento da baga e estádio final de maturação é desejável um período seco para produção de uva mais doce com polpa firme, sem rachadura, sem podridão e com vida de prateleira mais longa. Os ciclos de seis meses que compreendem as podas entre os meses de abril e junho satisfazem essas condições, com colheita prevista para os meses de setembro a novembro, onde o regime hídrico é quase nulo, ficando entre 10 e 15 mm em Canindé de São Francisco (Figura 1). O mesmo ocorre em Poço Redondo, onde a precipitação média fica no mesmo patamar nos meses de outubro e novembro.
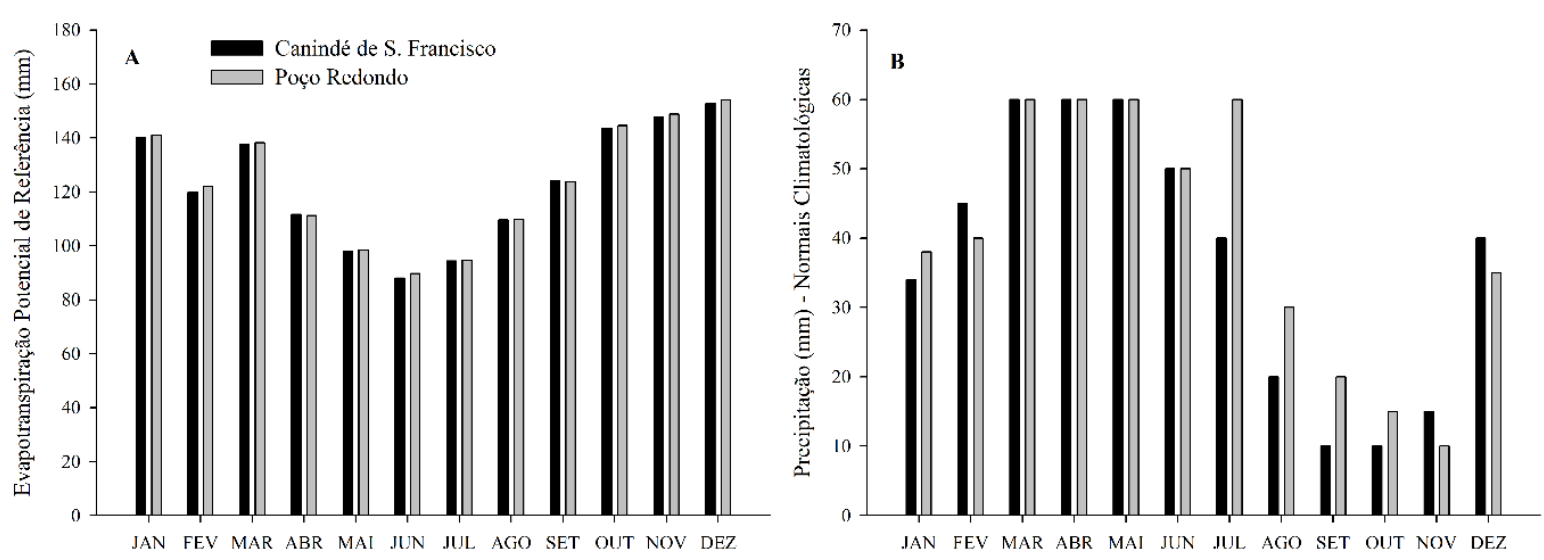

Figura 1. Evapotranspiração Potencial de Referência (A) e Precipitação (B) - Normais Climatológicas - 1961 a 1990 - para os municípios de Canindé de S. Francisco e Poço Redondo, Sergipe.

Em relação aos riscos climáticos, a região leva vantagem por não ocorrer formação de geadas e nem granizo, já que as temperaturas mínimas do ar, ao longo do ano, não chegam a menos que $18,5{ }^{\circ} \mathrm{C}$ (Figura 2). Outro ponto importante é a característica de baixa umidade relativa do ar, que decresce à medida que a temperatura do ar é elevada, o que está diretamente relacionada com o estado fitossanitário da cultura da videira, pois nesta condição, a maioria dos fungos não encontra um ambiente favorável para se desenvolver, obtendose uvas mais sadias, sem o uso excessivo de defensivos.

É necessário e de extrema importância também um manejo do dossel vegetativo nessas condições de clima quente (Figura 2), devendo proporcionar uma boa exposição foliar à radiação solar. Durante o período de maturação, a produção de uvas no alto sertão sergipano pode favorecer a evolução do teor de açúcar às uvas, 
pois tem ocorrência de dias ensolarados quase o ano inteiro.

Quanto à colheita, as condições tropicais da região possibilitam a programação de safras em qualquer mês do ano, o que pode ser um diferencial para a fabricação de vinhos com características sensoriais particulares em função da época de produção, e até da possibilidade de dupla poda anual. Porém, na produção de uvas americanas, por apresentarem baixo vigor, essas uvas não são normalmente conduzidas em sistema de dupla safra anual, pois de acordo com Kischino et al. (2007) as debilitariam com o tempo, provocando baixa fertilidade de gemas e brotação deficiente. Assim também ocorre com uvas finas de mesa e uvas destinadas a vitivinicultura, as quais demandam uma exigência térmica maior, o que pode não ser interessante para obtenção de frutos e vinhos de qualidade.

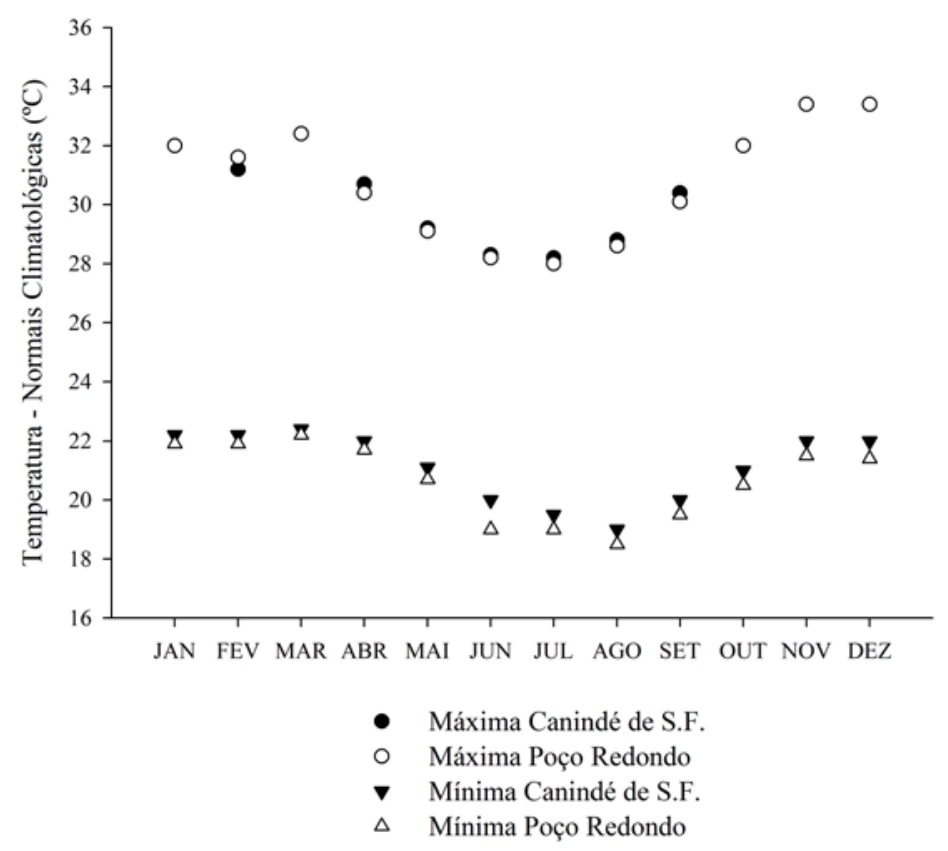

Figura 2. Temperaturas máximas e mínimas - Normais Climatológicas - para os municípios de Canindé de S. Francisco e Poço Redondo, Sergipe.

Camargo e Amorim (2007), em estudo com a região do Vale do Submédio do São Francisco, afirmam que a melhor qualidade das uvas é obtida quando a colheita é programada para o período mais seco do ano, confirmando a indicação dos meses de agosto a novembro como melhores para colheita na região do alto sertão sergipano.

Levando-se em consideração as exigências climáticas para os ciclos analisados de seis meses não há restrição para nenhuma das cultivares, compreendendo castas viníferas, que em geral são mais exigentes, como Cabernet Sauvignon e Syrah para elaboração de vinhos finos, e Itália e suas mutações (Rubi, Brasil, Benitaka) para uva de mesa.

Já para os períodos que compreendem quatro meses, o ciclo Primavera-Verão e Verão-
Outono são compatíveis com as cultivares das uvas Niagara Branca e Niagara Rosada, com exigência em torno de 1700 a 1800 GD, porém estas apresentam certa resistência em adaptação a climas quentes, necessitando de abundantes adubações orgânicas e controle da irrigação. Nos ciclos Outono-Inverno e Inverno-Verão, cultivares com exigência de até 1500 GD são recomendadas, como é caso das uvas sem sementes adaptadas às condições tropicais brasileiras BRS Morena, BRS Linda, e BRS Clara, bem como uvas finas de mesa também sem semente Superior Seedless e Marroo Seedless.

A aplicação desse modelo de estudo em menor escala permite identificar a viabilidade e o potencial produtivo da região, caracterizando suas possibilidades climáticas quanto as 
diferentes variedades e definindo melhores épocas para o cultivo da videira (poda/colheita). Entretanto, a realização de experimentos e estudos práticos é de fundamental importância para complementar as informações e nortear a recomendação de melhores castas e períodos.

\section{CONCLUSÕES}

1. O alto sertão sergipano apresenta condições favoráveis para o cultivo da videira, tanto para produção de uvas de mesa quanto para vitivinicultura, confirmando o potencial climático do semiárido brasileiro, surgindo como uma alternativa para os produtores diversificarem a produção e, se possível, obter duas safras anualmente, a depender da cultivar;

2. O clima vitícola do alto sertão sergipano é do tipo intra-anual, variando de acordo com o período de produção, semelhante a Petrolina/PE, no Submédio São Francisco.

3. Para o ciclo de quatro meses são indicadas podas nos ciclos Primavera-Verão e Verão-Outono para melhor aproveitamento e acúmulo térmico na região de estudo;

4. Para o ciclo de seis meses não há restrição térmica ao longo do ano, embora seja possível sincronizar o cultivo para colheita nos meses mais secos (agosto a novembro);

\section{REFERÊNCIAS BIBLIOGRÁFICAS}

ALLEN, R. G.; PEREIRA, L.; RAES, D.; SMITH, M. Crop evapotranspiration: guidelines for computing crop water requirements. In: FAO, 1998. (FAO. Irrigation and Drainage Paper, 56). Disponível em: < http://www.fao.org/docrep/X0490E/X0490E00. htm >. Acesso em 17 out. 2016.

BOLIANI, A.C. Avaliação fenológica de videira (Vitis vinifera) cv. Itália e Rubi na região Oeste do Estado de São Paulo. 1994. 188 f. Tese (Doutorado). Faculdade de Ciências Agrárias e Veterinárias, Universidade Estadual Paulista, Jaboticabal.
BOLIANI, A.C.; PEREIRA, F.M. Avaliação fenológica de videiras (Vitis vinifera L.) cultivares Itália e Rubi, submetidas à poda de renovação na região oeste do Estado de São Paulo. Revista Brasileira de Fruticultura, v.18, p.193-200, 1996.

CAMARGO, U. A.; AMORIM, F. M. de. Análise dos atuais sistemas de produção de uvas para vinho no Vale do São Francisco. Anais: A produção de vinhos em regiões tropicais. Bento Gonçalves: Embrapa Uva e Vinho, 2007. p. 97-101. (Embrapa Uva e Vinho. Documento, $60)$.

CAMARGO, U.A.; MANDELLI, F. Vênus uva precoce para mesa. Bento Gonçalves: Embrapa/CNPUV (Comunicado Técnico, n.13), 4p., 1993.

CAMARGO, U.A.; OLIVEIRA, P. R. D. Melhoramento genético. In: Leão, P. C. S., ed. Uva de mesa: produção - aspectos técnicos. Brasília: Embrapa Informação Tecnológica, p. 14-19. 2001.

HUGLIN, P. Nouveau mode d'évaluation des possibilités héliothermiques d'un milieu viticole. In: Symposium International sur l'Écologie de la Vigne, l, Constança, Roumanie, Ministère de l'Agriculture et de l'Industrie Alimentaire, p.89-98, 1978.

IBGE. Produção Agrícola Municipal. Lavouras Permanentes. Tabela 4.32 - Áreas destinada à colheita e colhida, quantidade produzida, rendimento médio e valor da produção de Uva, segundo as Grandes Regiões e Unidades da Federação produtoras, 2016.

KISHINO, A. Y.; CARVALHO, S. L. C. de; ROBERTO, S. R. Viticultura Tropical: o sistema de produção do Paraná. Londrina: IAPAR, 2007.

\section{LEÃO, P.C.S.; MAIA, J.D.G. Aspectos culturais em viticultura tropical uvas de mesa. Informe Agropecuário, v.19, p. 34-39, 1998.}


MOURA, M.S.B.; BRANDÃO, E.O.; SOARES, J.M.; DONOSCO, C.S.; SILVA, T.G. $\mathrm{F}$ da; SOUZA, L.S.B. Exigência térmica e caracterização fenológica da videira Cabernet Sauvignon no Vale São Francisco, Brasil. Congresso latinoamericano de viticultura y enologia, 11., 2007, Mendonza. Seduciendo al concumidor de hoy. Mendonza: IVV: CLEIFRA: SECYT, 2007 a.

MOURA, M.S.B.; BRANDÃO, E.O.; SOARES, J.M.; DONOSCO, C.S.; SILVA, T.G. F da; SOUZA, L.S.B. Exigência térmica e caracterização fenológica da videira Syrah no Vale São Francisco. Congresso brasileiro de Agrometeorologia, 15., 2007, Aracaju. Anais: Efeito das mudanças climáticas na agricultura. Aracaju: Sociedade Brasileira de Agrometeorologia: Embrapa Tabuleiros Costeiros, 2007. 1 CDROM. 2007 b.

MURAKAMI, K. R. N.; CARVALHO, A. J. C.; CEREJA, B. S.; BARROS, J. C. S. M.; MARINHO, C. S. Caracterização fenológica da videira cv. Itália (Vitis vinifera L.) sob diferentes épocas de poda na região norte do Estado do Rio de Janeiro. Revista Brasileira de Fruticultura, Jaboticabal - SP, v. 24, n. 3, p. 615-617, 2002.

NAGATA, R.K.; SCARPARE FILHO, J.A.; KLUGE, R.A.; VILLA NOVA, N.A. Temperatura-base e soma térmica (graus-dia) para videiras Brasil e Benitaka. Revista Brasileira de Fruticultura, v.22, p.329-333, 2000.

OLLAT, N.; DIAKOU-VERDIN, P.; CARDE, J. P.; BARRIEU, F.; GAUDILLÈRE, J. P.; MOING, A. Grape berry development: a review. Journal International des Sciences de la Vigne et du Vin, v.36, p.109- 131. 2002. https://doi.org/10.20870/oeno-

one.2002.36.3.970

ORDUÑA, R. M. de. Climate change associated effects on grape and wine quality and production. Food Research International, Davis, USA: Acta Horticulturae, v.43, p.1844-
1845.

2010.

https://doi.org/10.1016/j.foodres.2010.05.001

PEDRO JÚNIOR, M.J.; SENTELHAS, P.C.; POMMER, C.V.; MARTINS, F.P. Determinação da temperatura-base, graus-dia e índice biometeorológico para a videira Niagara Rosada. Revista Brasileira de Agrometeorologia, Santa Maria, v.2, p.51-56, 1994.

RIBEIRO, D. P., CORSATO, C. E, LEMOS, J. P., SCARPARE FILHO, J. Desenvolvimento e exigência térmica da videira Niagara Rosada cultivada no norte de Minas Gerais. Revista Brasileira de Fruticultura, Jaboticabal - SP, v. 31, n. 3, p. 890-895, 2009.

RIBEIRO, D.P., CORSATO, C.E., LEMOS, J.P., FRANCO, A.A.N., PIMENTEL, R.M.A.. Fenologia e exigência térmica da videira 'Benitaka' cultivada no norte de Minas Gerais. Revista Brasileira de Fruticultura., Jaboticabal - SP, v. 32, n. 1, p. 296-302, Março 2010.

RIBEREAU-GAYON, P.; DUBORDIEU, D.; DONÈCHE, B.; LONVAUD, A. Tratité d'Oenologie. Tome 1: Microbiologie du Vin. Vinifications, 5.ed. Dunod Paris,. 661p, 2004 a.

RIBEREAU-GAYON, P.; GLORIES, Y.; MAUJEAN, A.; DUBORDIEU, D. Tratité d'Oenologie. Tome 2: Chimie du vin. Stabilisation et traitements, 5.ed., Dunod Paris, 566p., 2004 b.

RIOU, C. Le déterminisme climatique de la maturation du raisin: application au zonage de la teneur em sucre dans la communauté européenne. Luxemburg: Office des Publications Officielles des Communautés Européennes, 322p., 1994.

SANTOS, A.E.O. ; SILVA, E.O. ; OSTER, A.H.; MISTURA, C.; SANTOS, M.O. Resposta fenológica e exigência térmica de uvas apirenas cultivadas no Submédio do São Francisco. Agrária (Recife. Online), v. 8, p. 364-369, 2013. 10.5039/agraria.v8i3a2313 
TERRA, M.M., PIRES, E.J.P., NOGUEIRA, N.A.M. Tecnologia para produção de uva Itália na região Noroeste do Estado de São Paulo. (Documento Técnico, 97). Campinas: CATI, 51p., 1998.

TONIETTO, J. Les macroclimats viticoles mondiaux et l'influence du mésoclimat sur la typicité de la Syrah et du Muscat de Hambourg dans le sud de la France: méthodologie de caractérisation (Tese de
Doutorado). Montpellier: École Nationale Supérieure Agronomique de Montpellier, 233p., 1999.

TONIETTO, J.; CARBONNEAU, A. A multicriteria climatic classification system for grape-growing regions worldwide. Agricultural and Forest Meteorology, 124/1-2, 81-97. 2004.

https://doi.org/10.1016/j.agrformet.2003.06.001 